\title{
Cardiovascular Drug Therapy during Interstage After Hybrid Approach: A Single-Center Experience in 51 Newborns with Hypoplastic Left Heart
}

\author{
Tino Mienert ${ }^{1} \cdot$ Anoosh Esmaeili ${ }^{2} \cdot$ Blanka Steinbrenner $^{1} \cdot$ Markus Khalil $^{1} \cdot$ Matthias Müller $^{1} \cdot$ Hakan Akintuerk $^{1}$. \\ Gunter Kerst ${ }^{3} \cdot$ Dietmar Schranz ${ }^{1,2}$
}

Accepted: 19 February 2021 / Published online: 13 March 2021

(c) The Author(s) 2021

\begin{abstract}
Background Newborns with hypoplastic left heart (HLH) are usually palliated with the Norwood procedure or a hybrid stage I procedure. Hybrid is our preferred approach. Given the critical relationship between stage I, interstage, and comprehensive stage II or advanced biventricular repair, we hypothesized that appropriate drug treatment is a significant therapeutic cornerstone, especially for the management of the high-risk interstage.

Methods We report a single-center observational study addressing the cardiovascular effects of, in particular, oral $\beta$-blockers and the additional use of angiotensin-converting enzyme (ACE) and mineralocorticoid inhibitors.

Results In total, 51 newborns-30 with HLH syndrome (HLHS) and 21 with HLH complex (HLHC) - with a median bodyweight of $3.0 \mathrm{~kg}$ (range 1.9-4.4; nine with bodyweight $\leq 2500 \mathrm{~g}$ ) underwent an uneventful "Giessen hybrid approach" using a newly approved duct stent. All patients were discharged home with a single, double or triple therapy consisting of B-blockers, ACE and mineralocorticoid inhibitors; $90 \%$ of the patients received bisoprolol, $10 \%$ received propranolol, $72 \%$ received lisinopril, and 78\% received spironolactone. Resting heart rate decreased from 138 bpm (range 112-172; $n=51$ ) at admission to $123 \mathrm{bpm}$ (range 99-139; $n=51$ ) at discharge and $110 \mathrm{bpm}$ before stage II/biventricular repair/ heart transplantation (range 90-140; $n=37$ ) accompanied by favorable bodyweight gain. No side effects were evident. Conclusion In view of drug risk/benefit profiles, as well as the variable morphology and hemodynamics, the highly selective $\beta 1$-adrenoceptor blocker bisoprolol is our preferred drug for treatment of HLHS/HLHC in the interstage. We avoid using ACE inhibitor monotherapy and exclude potential risks for coronary and cerebral perfusion pressure beforehand.
\end{abstract}

\section{Introduction}

Since 1998, our first choice of treatment for newborns with hypoplastic left heart syndrome (HLHS) or hypoplastic left heart complex (HLHC) has been the hybrid approach, with the aim of providing three-stage relief for patients with a single ventricle (SV) or of transferring advanced biventricular repair (BVR) from the neonatal

Dietmar Schranz

Dietmar.Schranz@paediat.med.uni-giessen.de

1 Pediatric Heart Center, Justus-Liebig University, Feulgenstrasse 12, 35385 Giessen, Germany

2 Pediatric Cardiology, University Clinic, Frankfurt, Germany

3 Pediatric Cardiology, University Clinic, Aachen, Germany

\section{Key Points}

The interstage after the Norwood/hybrid approach is a time of increased risk for babies born with hypoplastic left heart.

Success relies on heart protection and balancing of the systemic-pulmonary circulation. The long-acting $\beta 1$-adrenoceptor blocker bisoprolol can be used for both indications without any obvious adverse effects.

Based on our institutional experience, a $\beta 1$-selective adrenoceptor blocker is recommended as first-line treatment. Tissue angiotensin-converting enzyme inhibitors such as lisinopril should only be used in a combined therapy if no contraindications exist. 
period to later infancy [1]; in some cases, this approach has also been used as a bridge to heart transplantation (HTx). The Giessen hybrid approach is characterized by the fact that only the bilateral banding of the pulmonary artery branches (bPAB) requires open-chest surgery [2]. All other measures, such as duct stenting or manipulations of the atrial septum and aortic isthmus, are carried out via percutaneous transcatheter procedures. Our current survival rate of $78 \%$ after an average follow-up of almost 10 years (maximum 22 years) is acceptable but still leaves room for improvement [3-5]. One of the main reasons for our success in treating congenital heart defects, particularly those with SV physiopathology, has been the switch from a pressure-based to a flow-based treatment strategy [6]. In addition to the reduced use of perioperative $\beta$-adrenergic receptor agonists (i.e., catecholamines) and the preferred use of inodilators for acute treatment [2, 7-9], we have introduced cardioprotective drugs that support the fragile interstage with a pressure- and volume-loaded subpulmonary ventricle. In the absence of sufficient evidence-based randomized trials, cardiovascular drugs were selected based on their pharmacological profiles and age- and disease-related molecular differences between pediatric and adult heart failure [10-13]. We preferred a personalized concept of "responder phenotype" [14]. In our center, bisoprolol (a highly specific $\beta 1$-adrenoreceptor $\beta$-blocker), lisinopril (a tissue angiotensin-converting enzyme inhibitor [ACEI]), and spironolactone (a mineralocorticoid antagonist) are firmly established in the treatment of pediatric patients with heart failure with reduced ejection fraction, congenital left-right shunt defects, and-in particular-HLHS with a parallel connected lung and systemic circulation according to the hybrid approach [14]. As far as possible, we have avoided the chronic use of diuretics given their neurohumoral and cardiovascular effects. Instead, bisoprolol was used as a single cardiovascular drug or in combination with lisinopril and spironolactone as these drugs are long acting and easy to use so are readily accepted by the parents [14]. Accordingly, we report on our experience with oral drug treatment (bisoprolol-lisinopril-spironolactone) in 51 patients with HLHS, HLHC, and variants who were palliated with the Giessen hybrid stage I when a newly developed self-expandable stent (SinusSuperFlex-DS ${ }^{\circledR}$, OptiMed, Karlsruhe, Germany [SSF-DS]) was introduced at our institution for neonatal duct stenting. The main aim of our retrospective analysis was to present the efficacy and safety of a $\beta 1$-specific $\beta$-blocker alone or in combination with renin-angiotensin-aldosterone (RAAS) inhibitors during the susceptible interstage period, especially up to comprehensive stage II, but also BVR or HTx. To the best of our knowledge, the greatest benefit of $\beta$-blockers is shown in patients with a high pre-treatment heart rate (HR) or circulating norepinephrine levels [15] as is already found physiologically in catecholamine-driven cardiovascular systems of infants and young children. We did not use an ACEI as monotherapy without an accompanying $\beta$-blocker $[16,17]$.

\section{Methods}

Our retrospective observational study began in 2010 with the evaluation of the SSF-DS for the ductal stenting part of the Giessen hybrid stage I procedure in newborns with HLHS or HLHC according to ethical rules in place in our institution. Over a period of 5 years, we analyzed the clinical course of all hybrid-treated newborns who received the SSF-DS. Accordingly, we excluded all patients in whom the ductus arteriosus (DA) was not "stented" with an SSF-DS. The data analysis of the clinical course of included patients was based on medical reports, records, and all internal documentation of the Giessen \& Frankfurt Pediatric Heart Center from admission to discharge through to comprehensive stage II, BVR, or HTx. Table 1 summarizes the drugs in routine use with hybrid stage I. Resting HR was analyzed during the patient's sleep phase. In the intensive care unit, HR was determined from the patient file. The "Aristotle score" [18] was used for general risk assessment. Most of the data were examined descriptively. For this purpose, we obtained all relevant circulatory parameters, medications, peculiarities, and complications, as well as treatment up to stage II in patients with SV and HLHS or up to BVR in all other newborns with duct-dependent systemic blood flow.

\section{Results}

During the observation period, 51 patients (28 male; 55\%) received a Giessen hybrid approach using the SSF-DS without mortality; one patient died during the interstage (Fig. 1). The congenital heart defect was known prenatally in 35 patients $(69 \%)$. The median gestational age was 38 weeks (range 33-41), and the median body weight was $3.0 \mathrm{~kg}$ (range 1.9-4.4). Admission to our heart center took place at a mean age of 1.27 days (range 0-17). In total, 30 neonates had HLHS (57\% with aortic valve atresia), ten neonates had HLHC, six patients had borderline left ventricle, and two had congenital corrected transposition of the great arteries with hypoplastic systemic right ventricle, crisscross heart, or other complex cardiovascular diagnoses. Given the duct-dependent systemic blood flow, all patients received a continuous infusion of prostaglandin $\mathrm{E}_{1} 19 \mathrm{ng} / \mathrm{kg} / \mathrm{min}$ (range 5-170). The mean resting HR was 138 bpm (range 112-172). Tricuspid valve regurgitation of first or maximal second degree was registered in $21(41 \%)$ newborns. The 
Table 1 Interstage therapy for hypoplastic left heart syndrome or hypoplastic left heart complex

\begin{tabular}{|c|c|c|}
\hline Drug name & Dosage & Comments/surveillance \\
\hline Bisoprolol & $\begin{array}{l}0.05-0.1-(\max .0 .2) \mathrm{mg} / \\
\mathrm{kg} / \mathrm{d} \text { as a SD }\end{array}$ & $\begin{array}{l}\text { HR guided (aim } \mathrm{HR}<125 \mathrm{bpm} \text { at rest); adaption Rp to Rs (diastolic left-to-right shunt); almost } \\
\text { no contraindications }\end{array}$ \\
\hline Lisinopril & $\begin{array}{l}0.05-0.1-(\max .0 .2) \mathrm{mg} / \\
\mathrm{kg} / \mathrm{d} \text { as a SD }\end{array}$ & $\begin{array}{l}\text { Adaption to SAP/fluid status; not in case of rare diuretic treatment or compromised diuresis; not } \\
\text { indicated in (potential) obstructed aortic isthmus }\end{array}$ \\
\hline Spironolactone & $1-(2) \mathrm{mg} / \mathrm{kg} / \mathrm{d}$ as a SD & Anti-remodeling, not diuretic dosage (in advance of RV remodeling after stage II) \\
\hline Digoxin & $\begin{array}{l}\text { Saturation dosage } 0.01 \mathrm{mg} / \\
\mathrm{kg} / 8 \mathrm{~h} \\
\text { Daily dosage: } 0.008 \mathrm{mg} / \\
\mathrm{kg} / \mathrm{d} \text { (blood level: } \\
0.5-0.8 \mathrm{nmol} / \mathrm{l})\end{array}$ & HR control together with bisoprolol, if necessary \\
\hline Clopidogrel & $0.2 \mathrm{mg} / \mathrm{kg} / \mathrm{d}$ as a SD & No routine; only in case of complicated stenting of the DA, IAS, CoA \\
\hline
\end{tabular}

$C O A$ aortic coarctation, $D A$ ductus arteriosus, $H R$ heart rate, $I A S$ interatrial septum, $R p$ pulmonary vascular resistance, $R s$ systemic vascular resistance, $S A P$ systemic arterial blood pressure, $S D$ single dose

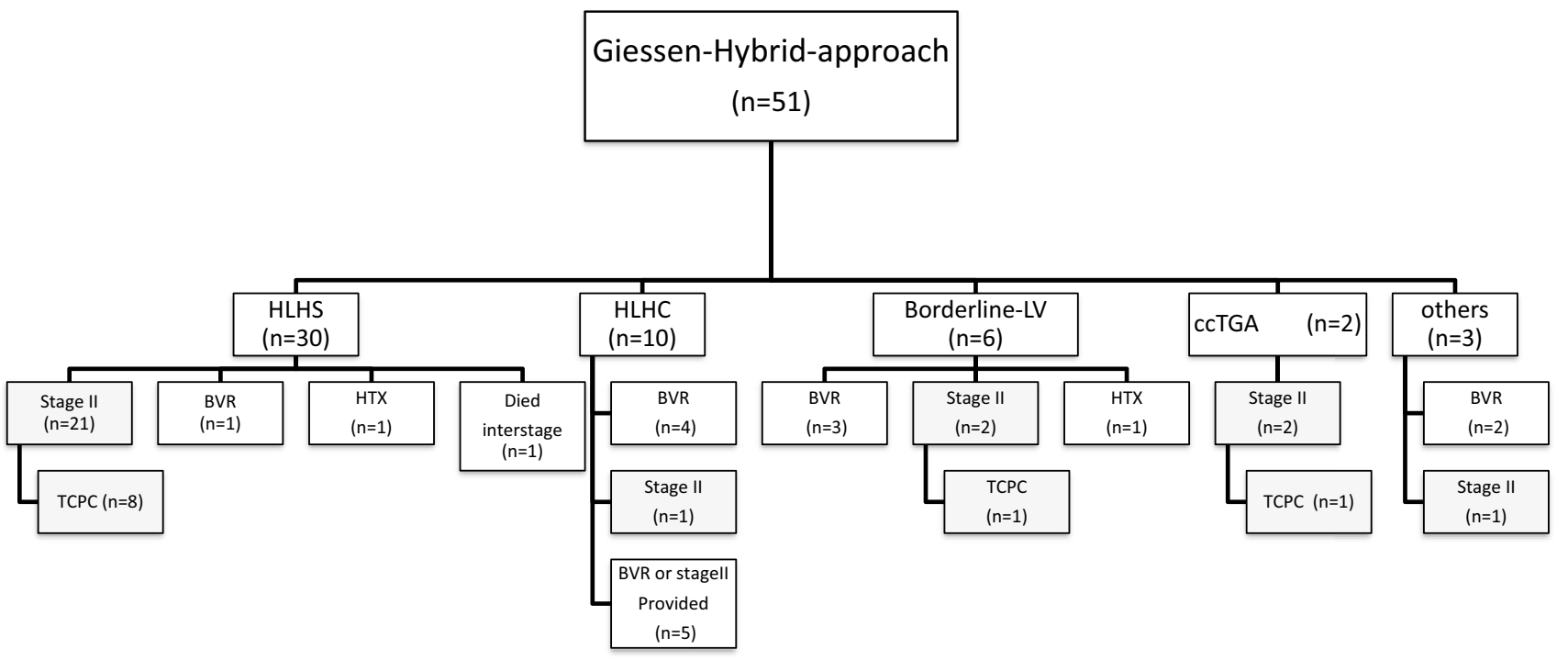

Fig. 1 Summary of the follow-up surgeries after hybrid stage I. $B V R$ biventricular repair, $c c T G A$ congenital corrected transposition of the great arteries, HLHC hypoplastic left heart complex, HLHS hypoplas-

"Giessen hybrid" procedure for patients with HLHS $(n=31)$ or HLHC $(n=21)$ was performed at a mean age of 6 days (range 1-50); nine patients had a body weight $<2500 \mathrm{~g}$. Overall, bilateral open-chest PAB was performed before ductal stenting, except in two cases where the sequence was reversed. DA stenting was performed in 19 of 51 patients (37\%) immediately after bPAB while they were still intubated and ventilated. Eight of the 19 ventilated patients were transferred directly from the operating room to the catheterization laboratory. The majority of patients received duct stenting and possibly other necessary percutaneous interventions while extubated and spontaneously breathing and with only mild analgosedation. The median Aristotle score of the HLHS and SV variants was 17.0 (range 14.5-21.5). tic left heart syndrome, $H T X$ heart transplantation, $L V$ left ventricle, $T C P C$ total cavo-pulmonary connection

Prior to the hybrid procedure, $16 \%$ of patients received bisoprolol, $4 \%$ lisinopril, $12 \%$ spironolactone, $24 \%$ furosemide, and $12 \%$ hydrochlorothiazide. Five patients (10\%) were treated with milrinone, and one also received norepinephrine. Immediately after the surgical bPAB, milrinone was used in eight patients, five with additional low-dose norepinephrine $(<0.1 \mu \mathrm{g} / \mathrm{kg} / \mathrm{min})$, and one in combination with adrenaline. In this context, it should be noted that the interatrial septum (IAS) had to be manipulated in 22 patients (43\%). Nine patients received an IAS stent as first-line treatment; four IAS stents were placed following primary balloon atrioseptostomy. In addition, 15 additional interventions on the already stented duct were required immediately or during the interstage. Seven additional stents were placed. Five 
patients required aortic manipulation; three isthmus stents were placed. A comprehensive stage II $(n=26)$ with an age of 134 days (range 86-276) was carried out during the study period. Fontan circulation had been completed in ten patients at the end of the observational period. The BVR was performed on ten infants at a mean age of 181 days (range 82-354). HTx was performed in two infants, 169 and 44 days after the hybrid approach, which had been performed with the aim of bridging to HTx. At the end of the data collection, all patients but one were discharged to home, at a mean age of 20 days (range 7-44), after the hybrid approach. At the time of writing, ten patients were awaiting comprehensive stage II and three BVR. There was a single death in the entire patient population, including all interventional and surgical procedures. The patient died of complications from cardiogenic shock when he was brought from home at the age of 52 days. He received an urgent stent placement to treat an obstructed aortic isthmus; however, he experienced hypoxic-ischemic encephalopathy, and treatment was ceased with parental consent.

As per institutional guidelines (Table 1), oral bisoprolol 0.1 to a maximum of $0.2 \mathrm{mg} / \mathrm{kg}$ was administered to $90 \%$ of all newborns and infants at discharge. The remaining $10 \%$ of patients with supraventricular tachycardia received the nonspecific $\beta$-blocker propranolol. Additional therapy with lisinopril took place in $73 \%$ and with spironolactone in $78 \%$ of the patients. One patient received furosemide and nine patients received low-dose hydrochlorothiazide; acetylsalicylic acid was not used. Four patients received clopidogrel $0.2 \mathrm{mg} / \mathrm{kg} /$ day, but most patients did not receive any antiaggregating drug. The mean resting HR decreased from $138 \mathrm{bpm}$ on admission (range 112-172 [ $n=51]$ ) to $123 \mathrm{bpm}$ at discharge (range 99-139 [ $\mathrm{n}=51]$ ) and $110 \mathrm{bpm}$ (range 90-140 [ $n=37]$ ) before stage II/BVR/ HTx. Upon discharge, all patients received food orally, with some also receiving food via gastric tube. Figure 2 summarizes the body weight gain progress in patients with HLHS.

Uncorrected body weight was between the 3rd and 25th percentile. No drug-related side effects were observed. No symptoms of $\beta$-blocker-related hypoglycemic episodes occurred, so no treatment was necessary. Parents easily learned and appreciated the daily administration of the drugs as single doses in similar dosage sizes.

\section{Discussion}

Mortality in newborns with HLHS and high-risk HLHC treated with the hybrid approach depends primarily on the quality of the surgical and catheter-based interventions. However, a good initial hybrid result does not guarantee a stable interstage up to a comprehensive stage II or BVR.

The interstage is a particularly vulnerable time for patients with HLHS $[3,19,20]$. The risk is lower in patients with adequate antegrade blood flow serving the
Fig. 2 Body weight data from patients with hypoplastic left heart syndrome at admission and discharge, and weight gain before comprehensive stage II

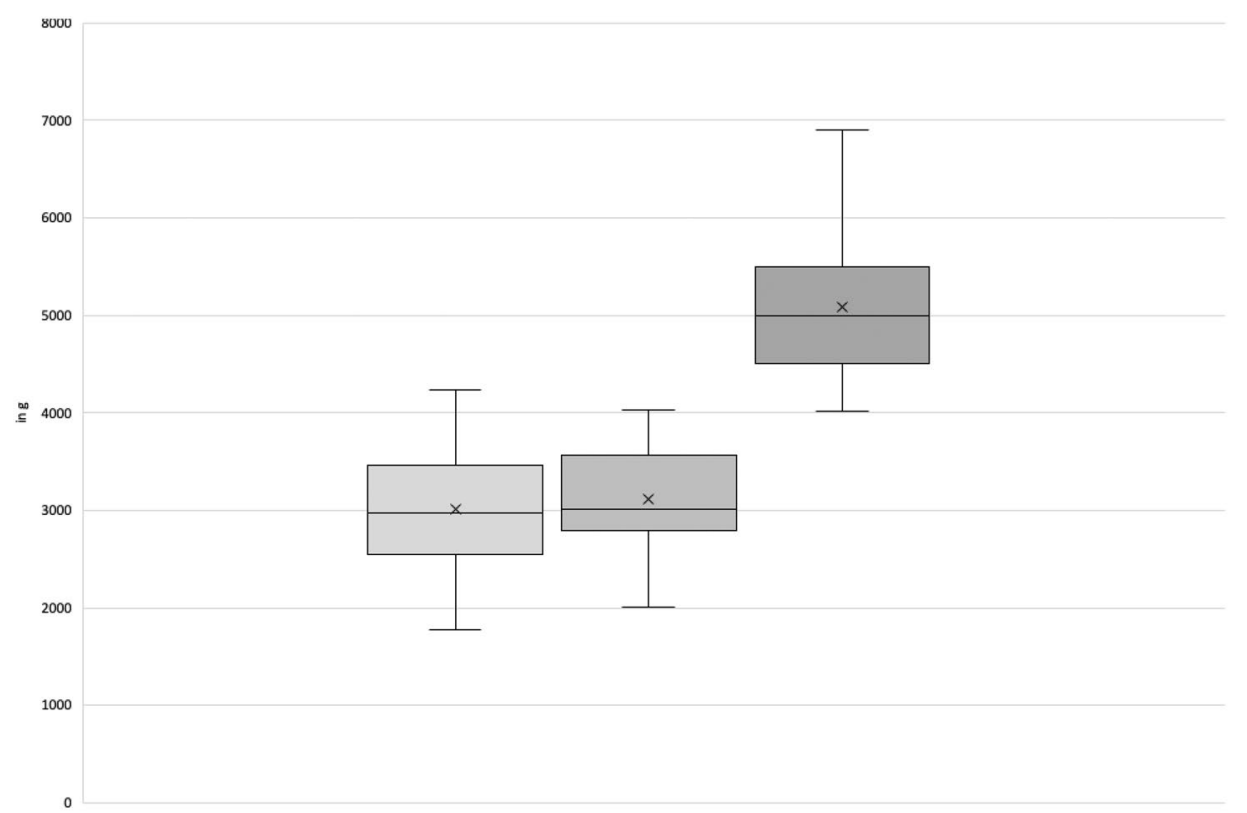


coronary arteries and cerebral perfusion. The Giessen hybrid stage I approach and follow-up operations, such as the comprehensive stage II, BVR, or HTx, were performed without mortality, but one patient died during the interstage. The cohort of 51 newborns presented a broad spectrum of HLH variants in which a novel self-expandable stent (SSF-DS) was used for the first time for ductal stenting and possibly also atrial septum. The main reason for the Giessen procedure, in which surgical bPAB and transcatheter ductal stenting are split up, is the need for additional manipulation of the atrial septum and delineation of the precise anatomy of the aortic-duct junction, which varies considerably from case to case. After the hybrid stage I, at least 34 patients $(67 \%)$ required additional transcatheter intervention either before discharge or later during the interstage, which reflects the vulnerability of patients at this point. The deceased patient experienced acute ischemia caused by an aortic isthmus obstruction, although a stent was still inserted as an emergency measure. Therefore, even with close monitoring by experienced pediatric cardiologists and parents well trained to observe their babies, interstage mortality cannot be completely avoided. Analyzing the additional influence of drug treatment on such a fragile cardiovascular condition remains difficult, especially if mortality is an endpoint of a study. Nor will a study design with evidence-based criteria work if mortality is dominated by drug-independent and more mechanical factors. Therefore, substitute pathophysiological and clinical criteria are preferred to analyze the risk-benefit profile of drugs used in a phase as difficult as that after hybrid stage I [14]. Although the interstage after the Norwood procedure is not directly comparable with that after hybrid stage I, the use of drug study resultswhether negative or positive-can only be limited. Nevertheless, two retrospective cohort studies reported that treatment with digoxin was associated with significantly reduced mortality in the interstage period after Norwood or Sano palliation [21, 22]. However, a prospective study would require inclusion of 1000 infants to allow an observed difference in interstage mortality of $10 \%$ in the no-digoxin and 5\% in the digoxin group if the interstage mortality was $8 \%$ and course performance was $80 \%$. Therefore, the interpretation of negative results from prospective randomized studies is even more problematic if results come from a patient cohort where mortality was influenced by several factors and where clinical syndromes such as heart failure, failing Fontan, or pulmonary arterial hypertension were not treated according to their clinical phenotypes. One consequence could be that good drugs are classified as inappropriate, as has already happened based on results of studies in carvedilol [23], enalapril [24], and sildenafil [25]. The carvedilol study [23] led to $\beta$-blockers being classified as unsuitable for the treatment of pediatric heart failure. Similarly, the enalapril study led to the drug being classified as ineffective in patients with a SV physiology [24]. Regarding these few studies, it has repeatedly been noted $[26,27]$ that evidence for the use of $\beta$-blockers and RAAS inhibitors in pediatric heart failure with biventricular physiology or as a therapeutic target for failing (right) SV are sparse. However, clinical experience (including parental observations of surrogate parameters such as heart and respiratory rate and nutritional improvement with subsequent body weight gain) and clinical condition are often neglected as scientific parameters. Since

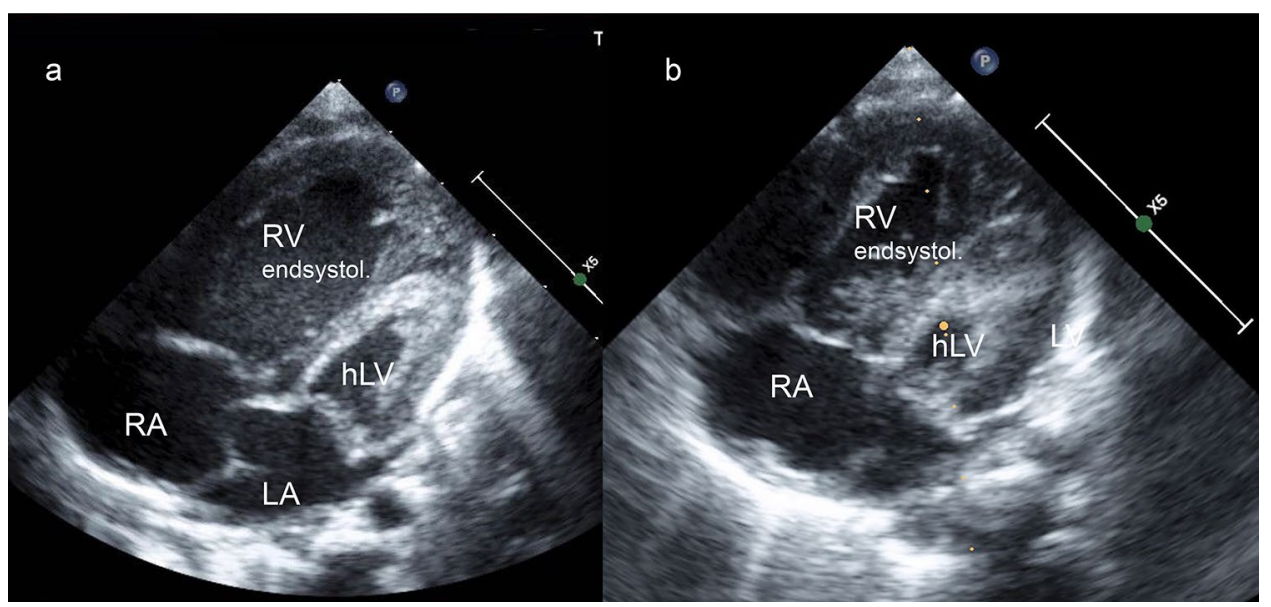

Fig. 3 Echocardiographic four-chamber view showing the volumeloaded RV in hypoplastic left heart syndrome before (a) and unloaded and hypertrophied after comprehensive stage II (b). Based on this well-known phenomenon following comprehensive stage II, we hypothesized that a bisoprolol-lisinopril-spironolactone treatment strategy might be beneficial to reduce the severity of a diastolic dysfunctional RV. $h L V$ hypoplastic left ventricle, $L A$ left artery, $L V$ left ventricle, $R A$ right artery, $R V$ right ventricle 
digoxin led to statistically reduced mortality between the stages, the reason for the improved survival rate due to digoxin remained unclear [21, 22]. Regardless of the narrow therapeutic range of digoxin, we believe that its ability to reduce HR outweighs the possible negative effects with restrictive ventricular physiology and increasing systemic vascular resistance (Fig. 3a,b). Therefore, in view of SV and left ventricle-borderline pathophysiology after hybrid stage I, and based on our clinical experience, we hypothesized that treatment with $\beta$-blockers would be beneficial for both an SV (right) and a borderline subaortic ventricle. An extension to a triple therapy with additional administration of a tissue angiotensin enzyme inhibitor and a mineralocorticoid inhibitor is considered if obvious side effects or contraindications are excluded. The highly specific $\beta 1$-adrenergic receptor blocker bisoprolol was used in $90 \%$ of our patients, whereas the nonspecific $\beta$-blocker propranolol was used in the other $10 \%$ of patients when its antiarrhythmic properties were more necessary and supraventricular tachycardia dominated. The main parameters of $\beta$-blocker effectiveness were HR monitoring and body weight gain up to stage II. Our therapeutic goal, which was almost always achieved, was an HR of $<120 \mathrm{bpm}$ with a normal respiratory rate at rest. No hemodynamic (drop in blood pressure) or metabolic (hypoglycemia) side effects requiring treatment were observed. We hypothesize that, in patients for whom oxygen delivery can only be increased to a limited extent, reducing oxygen consumption by lowering the HR to an individual optimum is the best strategy to enable good nutrition and avoid early stressors. Periods with increased myocardial metabolic demand, such as the higher HRs associated with stress and physical activity (e.g., crying), should be kept to a minimum to avoid the combination of reduced oxygen levels (additional hypoxemia in cyanotic patients) and myocardial ischemia. Patients with SV are at risk of inconsistent coronary blood flow, which is generally present because of anatomical considerations and a hypertrophied right ventricle [20]. An adequate diastolic time, which ensures adequate subendocardial blood flow, is essential for any ventricle operating at a systemic pressure level. This is especially true for a morphological right ventricle. One primary therapeutic goal to allow patients with parallel pulmonary and systemic circulation to achieve adequate systemic blood flow is also decreasing systemic vascular resistance without compromising coronary and cerebral perfusion pressure. In addition to clinical characteristics, such as feeding behavior, body weight gain, urine output, and sufficient blood pressure amplitude, the echocardiographic diastolic Doppler profile and the extent of diastolic left-right shunt through the (stented) duct are both important parameters for observing not only early coronary steal but also the quality of the medical drug therapy [14].

In summary, oral bisoprolol, a highly $\beta 1$-specific blocker, is safe and effective for use during the interstage following hybrid stage I. Bisoprolol can also be used in exceptional circumstances, such as in patients who receive catecholamines, to ensure adequate coronary perfusion pressure, with the goal being to avoid high HRs (when intravascular volume depletion is excluded) and harmful $\beta 1$-receptor agonistic side effects in the event of a failing biventricular or SV myocardium. Parents are carefully taught to monitor the surrogate parameters or HR and especially respiratory rate at rest; extensive monitoring of pulse oximetry at home is neither necessary nor comparably meaningful. We used the mineralocorticoid blocker spironolactone in relatively low, mainly non-diuretic dosages in approximately $80 \%$ of our patients, even though cardiac fibrosis is less pronounced in infants and small children [28]. Furthermore, we preferentially used the long-acting tissue ACEI lisinopril for additional balancing of pulmonary and systemic circulation, particularly in terms of persistence of high systemic vascular resistance following stage I. Long-term treatment with ACEIs seems to also be effective in reducing volume overload and ventricular hypertrophy in volume overloaded systemic ventricles of growing children [29]. However, unlike bisoprolol, the efficacy and safety of drugs such as spironolactone and lisinopril cannot easily be demonstrated by surrogate parameters. Therefore, when in doubt, ACEIs were not administered to patients at risk of inadequate retrograde aortic blood flow or any kidney problems. In view of the catecholamine-controlled cardiovascular physiology of newborns in particular, we avoid ACEI monotherapy, as was recently reported after Norwood stage I [17]. In our series, in which about $70 \%$ of the patients received combined treatment with the longacting lisinopril and the long-acting $\beta 1$-blocker bisoprolol, no side effects were observed. Furthermore, no electrolyte imbalances such as high potassium levels were observed, even with the addition of the potassium-sparing spironolactone. Theoretically, ACEI and renin escape can be avoided with the combination of a $\beta 1$-receptor blocker, but this was not analyzed in this study.

The limitations of our observational study relate to the design, the lack of data to support our hypothesis-driven drug therapy, and the lack of a control group. In addition, the hypothetical beneficial myocardial effects have not yet been systematically assessed or evaluated in randomized studies.

\section{Conclusion}

The drug treatment described is safe during interstage. In particular, bisoprolol monotherapy is the cornerstone of our interstage treatment. Triple drug therapy, particularly with 
an ACEI, can also be safely administered so long as volume depletion and retrograde aortic obstruction are excluded.

Given that increased systemic vascular resistance and end-diastolic ventricular pressures are an almost general feature after stage II or BVR of the borderline left ventricle, and not least in the de-privatized heart after Fontan completion, we hypothesized that a long-term strategy using triple therapy is promising, especially when compared with probably counterproductive chronic diuretic treatment. In the future, only individualized treatment with a "responder phenotype," based on a drug's pharmacological profile and tailored to the patient's specific pathophysiology and molecular mechanisms [30] will prevent heart failure in infants and children and improve our ability to satisfactorily treat it.

\section{Declarations}

Funding Open Access funding enabled and organized by Projekt DEAL.

Conflicts of interest Tino Mienert, Anoosh Esmaeili, Blanka Steinbrenner, Markus Khalil, Matthias Müller, Hakan Akintuerk, Gunter Kerst, and Dietmar Schranz have no conflicts of interest that are directly relevant to the content of this article.

Ethics approval The study was a retrospective analysis and followed the ethical rules of the institution.

Consent to Participate Not applicable.

Consent for publication Not applicable.

Availability of data and material Data and material collection of the manuscript are part of an ethical proofed thesis of cand. med. Tino Mienert (first author). Data are available on request.

\section{Code availability Not applicable.}

Author contributions TM was responsible for all data acquisition and the composition of both the manuscript and the figures. AE condensed the manuscript from the original thesis. BS, MK, MM, and HA were primarily responsible for patient treatment in the intensive care unit and catheterization laboratory as well as during anesthesia and surgeries. GK and DS (senior author) served the thesis and finalized the manuscript.

Open Access This article is licensed under a Creative Commons Attribution-NonCommercial 4.0 International License, which permits any non-commercial use, sharing, adaptation, distribution and reproduction in any medium or format, as long as you give appropriate credit to the original author(s) and the source, provide a link to the Creative Commons licence, and indicate if changes were made. The images or other third party material in this article are included in the article's Creative Commons licence, unless indicated otherwise in a credit line to the material. If material is not included in the article's Creative Commons licence and your intended use is not permitted by statutory regulation or exceeds the permitted use, you will need to obtain permission directly from the copyright holder. To view a copy of this licence, visit http://creativecommons.org/licenses/by-nc/4.0/.

\section{References}

1. Michel-Behnke I, Akintuerk H, Marquardt I, Mueller M, Thul J, Bauer J, Hagel KJ, Kreuder J, Vogt P, Schranz D. Stenting of the ductus arteriosus and banding of the pulmonary arteries: basis for various surgical strategies in newborns with multiple left heart obstructive lesions. Heart. 2003;89(6):645-50.

2. Zajonz T, Cupka P, Koerner C, Mann V, Menges T, Akintuerk $\mathrm{H}$, Valeske K, Thul J, Schranz D, Mueller M. Anaesthesia for bilateral pulmonary banding a spart of hybrid stage I palliating neonates with hypoplastic left heart syndrome. Paediatr Anaesth. 2020. https://doi.org/10.1111/pan.13876.

3. Schranz D, Bauer A, Reich B, Steinbrenner B, Recla S, Schmidt D, Apitz C, Thul J, Valeske K, Bauer J, Müller M, Jux C, MichelBehnke I, Akintürk H. Fifteen-year single center experience with the "Giessen Hybrid" approach for hypoplastic left heart and variants: current strategies and outcomes. Pediatr Cardiol. 2015;36(2):365-73.

4. Yerebakan C, Murray J, Valeske K, Thul J, Elmontaser H, Mueller M, Mann V, Ostermayer S, Latus H, Apitz C, Schranz D. Akintuerk H (2014) Long-term results of biventricular repair after initial Giessen hybrid approach for hypoplastic left heart variants. J Thorac Cardiovasc Surg. 2015;149:1112-20. https://doi. org/10.1016/j.jtcvs.2014.09.028.

5. Yerebakan C, Valeske K, Elmontaser H, Yörüker U, Mueller M, Thul J, Mann V, Latus H, Villanueva A, Hofmann K, Schranz D. Akintuerk H (2015) Hybrid therapy for hypoplastic left heart syndrome: myth, alternative, or standard? J Thorac Cardiovasc Surg. 2016;151:1112-21.

6. Tweddell JS, Hoffman GM, Mussatto KA, Fedderly RT, Berger S, Jaquiss RD, Ghanayem NS, Frisbee SJ, Litwin SB. Improved survival of patients undergoing palliation of hypoplastic left heart syndrome: lessons learned from 115 consecutive patients. Circulation. 2002;106:82-9.

7. Hoffman TM, Wernovsky G, Atz AM, Kulik TJ, Nelson DP, Chang AC, Bailey JM, Akbary A, Kocsis JF, Kaczmarek R, Spray TL, Wessel DL. Efficacy and safety of milrinone in preventing low cardiac output syndrome in infants and children after corrective surgery for congenital heart disease. Circulation. 2003;107(7):996-1002.

8. Burkhardt BE, Rucker G, Stiller B. Prophylactic milrinone for the prevention of low cardiac output syndrome and mortality in children undergoing surgery for congenital heart disease. Cochrane Database Syst Rev. 2015(3):CD009515 (Circ Heart Fail. 2015; 8(1): 57-63).

9. Nakano SJ, Nelson P, Sucharov CC, Miyamoto SD. Myocardial response to milrinone in single right ventricle heart disease. $\mathrm{J}$ Pediatr. 2016;174:199-203.

10. Miyamoto SD, Stauffer BL, Nakano S, Sobus R, Nunley K, Nelson $\mathrm{P}$, Sucharov CC. Beta-adrenergic adaptation in paediatric idiopathic dilated cardiomyopathy. Eur Heart J. 2014;35:33-41.

11. Miyamoto SD, Stauffer BL, Polk J, Medway A, Friedrich M, Haubold K, Peterson V, Nunley K, Nelson P, Sobus R, Stenmark $\mathrm{KR}$, Sucharov CC. Gene expression and $\beta$-adrenergic signaling are altered in hypoplastic left heart syndrome. J Heart Lung Transplant. 2014;33(8):785-93.

12. Nakano SJ, Sucharov J, Van R, Cecil M, Nunley K, Wickers S, Karimpur-Fard A, Stauffer BL, Miyamoto SD, Sucharov CC. Cardiac adenylyl cyclase and phosphodiesterase expression profiles vary by age, disease, and chronic phosphodiesterase inhibitor treatment. J Card Fail. 2016;23:72-80. https://doi.org/10.1016/j. cardfail.2016.07.429.

13. Stauffer BL, Russell G, Nunley K, Miyamoto SD, Sucharov CC. miRNA expression in pediatric failing human heart. J Mol 
Cell Cardiol. 2013;57:43-6. https://doi.org/10.1016/j.yjmcc 2013.01.005.

14. Schranz D, Voelkel N. Nihilism of chronic heart failure therapy in children and why effective therapy is withheld. Eur J Pediatr. 2016;175(4):445-55.

15. Packer M. The neurohormonal hypothesis: a theory to explain the mechanism of disease progression in heart failure. J Am Coll Cardiol. 1992;20:248-254.

16. Buchhorn R, Ross RD, Hulpke-Wette M, Bartmus D, Wessel A, Schulz R, Joachim B. Effectiveness of low dose Captopril versus Propranolol therapy in infants with severe congestive failure due to left-to-right shunts. Int J Cardiol. 2000;76(2-3):227-33.

17. Hansen JE, Brown DW, Hanke SP, Bates KE, Tweddell JS, Hill G, Anderson JB. Angiotensin-converting enzyme inhibitor prescription for patients with single ventricle physiology enrolled in the NPC-QIC registry. J Am Heart Assoc. 2020;9:e014823.

18. Lacour-Gayet F, Clarke DR. Aristotle Committee. The Aristotle method: a new concept to evaluate quality of care based on complexity. Curr Opin Pediatr. 2005;17(3):412-417.

19. Ohye RG, Schranz D, Yves D'Udekem. Current therapy for hypoplastic left Heart Syndrome and related single ventricle variants. Circulation. 2016;134:1265-127.

20. Hoffman GM, Scott JP, Ghanayem NS, Stuth EA, Mitchell ME, Woods RK, Hraska V, Niebler RA, Bertrandt RA, Mussatto KA, Tweddell JS. Identification of time-dependent risks of hemodynamic states following stage 1 norwood palliation. Ann Thorac Surg (August 9, 2019). https://doi.org/10.1016/j.athoracsur .2019.06.063.

21. Oster ME, Kelleman M, McCracken C, Ohye RG, Mahle WT. Association of digoxin with interstage mortality: results from the pediatric heart network single ventricle reconstruction trial public use dataset. J Am Heart Assoc. 2016; 5(1):e002566. https://doi. org/10.1161/jaha.115.002566.

22. Brown DW, Mangeot C, Anderson J, Peterson LE, King E, Lihn S, Neish S, Beekman R, Lannon C. Digoxin use at discharge is associated with reduced interstage mortality after stage I palliation for single ventricle heart disease. J Am Coll Cardiol. 2015. https ://doi.org/10.1016/s0735-1097(15)60488-0(Abs).

23. Shaddy RE, Boucek MM, Hsu DT, Boucek RJ, Canter CE, Mahony $\mathrm{L}$, et al. Carvedilol for children and adolescents with heart failure: a randomized controlled trial. JAMA. 2007;298:1171-9.

24. Hsu DT, Zak V, Mahony L, Sleeper LA, Atz AM, Levine JC, et al. Enalapril in infants with single ventricle: results of a multicenter randomized trial. Circulation. 2010;122:333-40.

25. Barst RJ, Ivy DD, Gaitan G, Szatmari A, Rudzinski A, Garcia AE, Sastry BK, Pulido T, Layton GR, Serdarevic-Pehar M, Wessel DL. A randomized, double-blind, placebo-controlled, dose-ranging study of oral sildenafil citrate in treatment-naïve children with pulmonary arterial hypertension. Circulation. 2012;125(2):324-34.

26. Burns KM, Byrne BJ, Gelb BD, Kühn B, Leinwand LA, Mital S, Pearson GD, Rodefeld M, Rossano JW, Stauffer BL, Taylor MD, Towbin JA, Redington AN. New mechanistic and therapeutic targets for pediatric heart failure: report from a National Heart Lung, and Blood institute working group. Circulation. 2014;130(1):79-86.

27. Garcia MA, Beatty JT, Nakano SJ. Heart failure in single right ventricle congenital heart disease: physiologic and molecular considerations. Am J Physiol Heart Circ Physiol. 2020;318(4):H947-65.

28. Nakano SJ, Siomos AK, Garcia AM, Nguyen H, SooHoo M, Galambos C, Nunley K, Stauffer BL, Sucharov CC, Miyamoto $\mathrm{SD}$. Fibrosis related gene expression in single ventricle heart disease. J Pediatr. 2017;191:82-90.

29. Mori Y, Nakazawa M, Tomimatsu H, Momma K. Long-term effect of angiotensin- converting enzyme inhibitor in volume overloaded heart during growth: a controlled pilot study. J Am Coll Cardiol. 2000;36:270-5.

30. Saraf A, Book WM, Nelson TJ, Xu C. Hypoplastic left heart syndrome: from bedside to bench and back. J Mol Cell Cardiol. 2019;135:109-18. 